\title{
P25 Scoring Method for the Assessment of R/C
}

\section{Buildings}

\author{
Kubilay Kaptan \\ Disaster Education, Application and Research Center, Istanbul Aydin University, Istanbul 34295, Turkey
}

\begin{abstract}
An effective rapid assessment technique, called "P25 Scoring Method", has been developed and tested on 26 different case studies recently, in order to predict the collapse vulnerability of the R/C buildings. After a short description of the approach, the study presents the sensitivity study of the method to the selected structural parameters by considering incremental deviation of the final scores from the base model. Further, the methodology was applied to an additional 100 damaged buildings in order to check the reliability of the method and some necessary modifications have been applied to the algorithm after considering this larger database. The evaluation of the results has been interpreted as a beneficial guidance for local authorities. The risk bands are defined according to the final scores and the effect of changing the band-width has also been studied through a safe but an economical procedure. A satisfactory correlation of the method with real damage states is obtained and a ready-to-use methodology has been introduced for future studies.
\end{abstract}

Key words: Rapid assessment technique, P25 scoring method, R/C Buildings.

\section{Introduction}

Extensive damages to buildings during the recent strong earthquakes in Turkey forced the municipal authorities to utilise some rapid assessment techniques in order to evaluate the existing massive building stock in terms of life safety. Immediately following the Kocaeli, Bolu and Duzce earthquakes of 1999, there was a tendency to try to retrofit any and all types of reinforced concrete buildings, which are determined, by analytical means, to be "unsafe" or "inadequate" in accordance with the current Turkish Earthquake Code of 1998. With regard to the high level of code requirements and the risk zones, experienced engineers agree on the fact that almost all of the building stock is far from satisfying the recent code requirements. It was soon realized however, that the approach to evaluate and retrofit every single building according to current code requirements would entail unprecedented difficulties. For instance,

Corresponding author: Kubilay Kaptan, assistant professor, research fields: civil engineering, disaster management, structural analysis and risk management. E-mail: kubilaykaptan@aydin.edu.tr. it would require a minimum of 25 billion US dollars and a time period of 25 years to retrofit the so-called "unsafe" buildings in the Municipality of Istanbul [1-4]. Furthermore, the legal disputes among the property owners of the condominiums, as to the necessity, type and extent of the retrofit, would be insurmountable.

Starting from 1992 Erzincan, Turkey earthquake, researchers developed some clear-cut and so-called rapid screening techniques, not necessarily to define the safety according to the codes but to assess the collapse vulnerability of every individual building [5-12].

The authors recently developed a rapid assessment technique called as "P25 Scoring Method" and verified its accuracy using 26 partly and totally collapsed buildings [13, 14]. The detailed explanations of the theoretical background and the general discussions are not given here since the sole aim of this paper is to verify further the accuracy of the previously presented P25 Scoring Method with an increased number of case study buildings and finally to evaluate the effect of security bands in terms of life 
safety and cost, in addition to defining the sensitivity of the key parameters of the method.

\section{An Overview of the "P25 Scoring Method"}

The method is primarily based on observing and listing the most important structural parameters which affect the seismic response of a building and also scoring them with some weighting factors one after the other in relation to their relative importance. In order to execute the P25 Scoring Method, some 25 different structural features of the investigated building are either measured or observed visually and then the total score is determined by means of simple calculations. The basic parameters of the proposed P25 Scoring Method may be listed as: (1) plan dimensions of R/C columns, shear walls and infill walls at ground floor, (2) storey heights $h_{i}$ and the total height $H$, (3) outer plan dimensions of ground floor, (4) typical beam dimensions, (5) effective ground acceleration, (6) building importance factor, (7) soil conditions and soil profile, (8) other observational parameters like material quality, confinement zones of columns, irregularities such as, short columns, soft storey, etc..

\subsection{Basic Definitions}

In order to avoid any possible differences of interpretations by different engineers, and to minimize the influence of human based uncertainties, some basic definitions and clarifications are given below.

Commonly, for the building stock in Turkey, the most damage vulnerable storey of the building is ground floor which is called as the "critical storey". However, some exceptions to this rule of thumb may exist, thus, to be on the safe side, all possible storeys should be checked and the storey which gives the smallest score should be accepted as the final score of the building. Plan dimensions $L_{x}$ and $L_{y}$ are the $x$ and $y$-sides of the smallest rectangle into which the plan of the critical storey may be placed. Thus, the building with irregular plan dimensions will be penalized in scoring by considering a relatively larger plan area than the actual. Eventually, for the critical storey, the floor area will be calculated as $A_{p}=L_{x} L_{y}$ and the moment of inertia values will be calculated as $I_{p x}=L_{y} L_{x}^{3} / 12$ and $I_{p y}$ $=L_{x} L_{y}{ }^{3} / 12$.

If a masonry infill wall fills in the complete void between the columns and beams of a frame or if it is in contact with a column then it should be included totally in the calculations. For the infill walls along the perimeter of a floor however, the thickness of the infill wall is recommended to be taken as one half of the real thickness, if there are window openings in the infill wall. If a perimeter wall has a window opening not in the middle but at the edge, then the length of the solid portion of the wall should be taken as the length disregarding the window opening and the full thickness should be considered.

Since the proposed method is developed for structural members with rectangular cross sections located in orthogonal Cartesian direction of axes, then there will be a necessity for some compensation for members with non rectangular shapes and/or skewed orientation. In such non orthogonal and non rectangular cases, the total area and the total moments of inertia of the element are calculated in its local axes and then they are projected to the global Cartesian directions of axes of the building.

\subsection{Effective Resultant Rigidities}

The effective resultant rigidity $C_{A r}$ of the cross-sectional areas and the effective resultant flexural rigidity $C_{I r}$ of the critical storey are calculated as:

$$
\begin{aligned}
C_{A r} & =\left[\left(0.87 C_{A, \min }\right)^{2}+\left(0.5 C_{A, \text { max }}\right)^{2}\right]^{0.5} \\
C_{I r} & =\left[\left(0.87 C_{I, \text { min }}\right)^{2}+\left(0.5 C_{I, \text { max }}\right)^{2}\right]^{0.5}
\end{aligned}
$$

The total effective area and the total flexural rigidity parameters are calculated using the following expressions, Eqs. (3) and (4), for both $x$ and $y$-directions. The smaller and larger of the $x$ and $y$-components of these effective areas and rigidities are entered as minimum and maximum values, respectively, in Eqs. (1) and (2): 


$$
\begin{gathered}
C_{A X}=9\left(10^{5}\right)\left(\sum A_{e f, x}\right) / A_{p} \\
C_{I X}=9\left(10^{5}\right)\left[\left(\sum I_{e f, x}\right) / I_{p X}\right]^{0.4}
\end{gathered}
$$

in which

$$
\begin{aligned}
A_{e f, x} & =A_{c}+A_{s x}+0.15 A_{w x} \\
I_{e f, x} & =I_{c x}+I_{s x}+0.15 I_{w x}
\end{aligned}
$$

where,

$A_{p}=$ Floor plan area of the critical storey $\left(A_{p}=\right.$ $\left.L_{x} L_{y}\right)$;

$A_{c}=$ Cross-sectional area of a column;

$A_{s x}, A_{w x}=$ Cross-sectional area of the $\mathrm{R} / \mathrm{C}$ shear wall, and infill masonry wall, respectively;

$I_{p x}=L_{y} L_{x}{ }^{3} / 12$;

$I_{p y}=L_{x} L_{y}{ }^{3} / 12$;

$I_{c x}=$ Moment of inertia of a column about $y$-axis;

$I_{s x}, I_{w x}=$ Moments of inertia of the R/C shear wall, and infill masonry wall, about $y$-axis, respectively.

For $x$-direction calculations, the $\mathrm{R} / \mathrm{C}$ shear walls and infill masonry walls extending in $x$-direction only will be taken into account, and only the moments of inertia values about $y$-axis will be included in $I_{s x}$ and $I_{w x}$ parameters. Conversely, in $y$-direction calculations, the $\mathrm{R} / \mathrm{C}$ shear walls and infill masonry walls extending in $y$-direction only will be taken into account, and only the moments of inertia values about $\mathrm{x}$-axis will be included in $I_{s y}$, and $I_{w y}$-parameters.

Since the order of magnitude of the cross-sectional area values are much smaller than those of the respective moment of inertia values, in order to be able to use them in the same formula, the power of 0.4 is added to the expression in Eq. (4). The cross-sectional area and the moment of inertia values of the masonry infill walls are multiplied by 0.15 in Eqs. (5) and (6), in order to represent the ratio of the modulus of elasticity of a masonry wall to that of concrete.

The total effective area and flexural rigidity $C_{A}$ and $C_{I}$ in $x$-direction are not necessarily equal to their counterparts in $y$-direction. Usually, the total effective rigidity in one direction may be less than that in the other direction. Thus to be more realistic, the dominant direction of earthquake may be assumed to make a 30-degree angle with the weak direction of the building.
Consequently, a resultant effective area $C_{A r}$ and also a resultant effective flexural rigidity $C_{I r}$ should be calculated, as given by Eqs. (1) and (2). The coefficients 0.87 and 0.5 in those expressions represent $\operatorname{Cos} 30^{\circ}=0.87$ and $\operatorname{Sin} 30^{\circ}=0.50$ values, respectively.

\subsection{Adjustment for Overall Height}

Since the cross-sectional dimensions of the vertical structural elements at ground floor (critical storey) increase with the overall height $H$ of the building, it should also be included as another parameter in the strength evaluation calculations. As the number of storeys increases, the mass as well as the base shear will also increase. On the other hand, depending on the soil profile, the base shear coefficient obtained from the response spectrum gradually decreases as the overall height of the building increases. Therefore, for low and medium rise buildings, the increase in height adversely affects the strength parameters. For taller buildings, however, the increase in height has a favorable effect in the calculation of effective strength parameters. Considering all these variations, a suitable correction factor $t_{0}$ is proposed in Eq. (7), which represents both the adverse and favorable effects of the building height. The correction factor $t_{0}$ is given as

$$
t_{0}=90+40 \mathrm{H}-0.7 \mathrm{H}^{2}
$$

\subsection{Final Score}

Once the effective resultant cross-sectional area $C_{A r}$ and the effective resultant flexural rigidity $C_{I r}$ of the critical storey are available from Eqs. (1) and (2), and also the height correction factor $t_{0}$ is evaluated, then the final score $P$ of the P25 Scoring Method is obtained from:

$$
P=\left[\left(C_{A r}+C_{I r}\right) / t_{0}\right] \prod_{i=1}^{25} f_{i}
$$

where, $f_{i}$ represents 25 different correction factors, concerning the status and various deficiencies of the building. They are obtained by observational and/or quantitative means as outlined in the next section. The final $P$ score of the building is expected to possess a 
value between 0 and 100. Theoretically, for very well-built extra strong structures, it is possible to obtain a score greater than 100 .

\subsection{Correction Factors $-f_{i}$}

Some of the correction factors $\left(f_{1}-f_{11}\right.$ and $\left.f_{17}-f_{25}\right)$ are qualitative in nature, representing the structural irregularities, material quality, foundation type, soil conditions, etc., while some others $\left(f_{12}-f_{16}\right)$ are quantitative in nature to be calculated by means of rigorous expressions as supplied herein. The ranges of numerical values for the qualitative correction factors are given in Tables 1 and 2 .

2.5.1 Quantitative Correction Factors $f_{12}$ to $f_{16}$
The soft storey correction factor $f_{12}$ is calculated as follows:

$$
f_{12}=\left[\alpha_{a} r_{f}\left(h_{i+1} / h_{i}\right)^{3}\right]^{0.15} \leq 1
$$

where,

$$
\begin{gathered}
r_{a}=\left(\sum A_{e f}\right)_{i} /\left(\sum A_{e f}\right)_{i+1} \leq 1 \\
r_{f}=\left(\sum I_{e f}\right)_{i} /\left(\sum I_{e f}\right)_{i+1} \leq 1 \\
\alpha_{a}=1+0.4\left(r_{a}-1\right) .
\end{gathered}
$$

As seen above, the correction factor of soft storey is represented by both the effective cross-sectional areas and the moments of inertia ratios of columns, R/C shear walls and masonry infill walls at the $(i)^{\text {th }}$ and $(i+1)^{\text {th }}$ storeys, as one proceeds from bottom to top. The $h_{i}$ and $h_{i+1}$ values are the heights of the critical

Table 1 Qualitative correction factors ${ }^{(1)}$.

\begin{tabular}{|l|l|l|l|}
\hline Symbol & Definition & Low risk & High risk \\
\hline$f_{1}$ & Torsional irregularity ${ }^{(2)}$ & Minor: 0.98 & Major: 0.96 \\
\hline$f_{2}$ & Floor discontinuities $^{(2)}$ & Exists locally: 0.98 & Exists widely: 0.96 \\
\hline$f_{3}$ & Discontinuity of vertical elem. ${ }^{(2)}$ & Exists locally: $0.84-0.92$ & Exists widely: $0.60-0.68 / 0.74$ \\
\hline$f_{4}$ & Mass irregularity & Exists locally: 0.99 & Exists widely: 0.98 \\
\hline$f_{5}$ & Corrosion & Local corrosion: 0.98 & General corrosion: 0.96 \\
\hline$f_{6}$ & Short column & Exists locally: 0.96 & Exists all around: 0.92 \\
\hline$f_{7}$ & Heavy facade elements & Exists locally: 0.98 & Exists mainly: 0.96 \\
\hline$f_{8}$ & Intermediate floors & Less than $25 \%: 0.95$ & More than $25 \%: 0.90$ \\
\hline$f_{9}$ & Possibility of pounding & Low risk: 0.90 & High risk: 0.80 \\
\hline$f_{10}$ & Staggered levels of floors & Exists locally: 0.90 & Exists all around: 0.80 \\
\hline$f_{11}$ & Quality of concrete & Between C10 and C16: 0.90 & Less than C10: 0.80 \\
\hline
\end{tabular}

(1) If the respective weakness does not exist, the correction factor will be taken as 1.00;

(2) The definitions of $f_{1}, f_{2}$ and $f_{3}$ irregularities are the same as those defined in the Turkish Earthquake Code of 1998. (The Code may be downloaded from: http://www.koeri.boun.edu.tr/depremmuh/FINEND-999.pdf.)

Table 2 Soil and foundation based correction factors ${ }^{(1)}$.

\begin{tabular}{|l|l|l|l|}
\hline Symbol & Definition & Low risk & High risk \\
\hline$f_{17}$ & Soil type ${ }^{(2)}$ & Z2, Z3, Z4 soil type (A, B, C, D soil type): 0.96 & Z1 soil type (E, F, G soil type): 0.92 \\
\hline$f_{18}$ & Soil settlement potential & Low risk: 0.98 & High risk: 0.96 \\
\hline$f_{19}$ & Liquefaction potential & Low risk: 0.98 & High risk: 0.96 \\
\hline$f_{20}$ & Landslide potential & Low risk: 0.98 & High risk: 0.96 \\
\hline$f_{21}$ & Soil amplification potential & Low risk: 0.90 & High risk: 0.75 \\
\hline$f_{22}$ & Topographic effects & On a slope: 0.90 & On top of a hill: 0.80 \\
\hline$f_{23}$ & Foundation type & Continuous footings: 0.98 & $\begin{array}{l}\text { Individual footings w/or w/o tie beams: } \\
0.96-0.94\end{array}$ \\
\hline$f_{24}$ & Foundation depth & Between 1.0 and $4.0 \mathrm{~m}: 0.98$ & Less than $1.0 \mathrm{~m}: 0.96$ \\
\hline$f_{25}$ & Ground water table & Between 5.0 and $10.0 \mathrm{~m}: 0.99$ & Less than $5.0 \mathrm{m:} 0.98$ \\
\hline
\end{tabular}

(1) If the respective weakness does not exist, the correction factor will be taken as 1.00;

(2) Soil type stiffness decreases from Z1 to Z4 in the Turkish Earthquake Code of 1998. 
storey $i$ and of the upper storey $i+1$, respectively. The parameters, $A_{c}, A_{s}$ and $A_{w}$ represent the cross-sectional areas of columns, shear walls, and infill walls. Similarly, the parameters $I_{c}, I_{s}$ and $I_{w}$ represent the moments of inertia of columns, shear walls, and infill walls, respectively. The calculations for $r_{a}$ and $r_{f}$ values will be computed in both $x$ and $y$-directions. But, the minimum values will be utilized in Eq. (9) as a rule.

In order to consider the influences of both shear and bending rigidities in the same formula, the differences in the order of magnitudes of those two parameters should be vanished. For this purpose, the contribution of the $r_{a}$-value into Eq. (9) is elevated by means of an auxiliary parameter $\alpha_{a}$, as defined in Eq. (12), which introduces a weighting factor of 0.40 to represent approximately the ratio of shear modulus $G$ to elastic modulus $E$. The 0.15 th power is introduced to the whole formula in Eq. (9) order to obtain a reasonable value for $f_{12}$ between 0 and 1 .

The strong column-"weak" beam concept, which is defined as one of the key provisions in most of the recent earthquake codes, is also considered as a quantitative parameter $f_{13}$ in the proposed method. Instead of calculating the ultimate plastic moment capacities of columns and beams meeting at a joint, the flexural rigidities of columns and beams are taken as criteria. Hence, the correction factor $f_{13}$ is defined as

$$
f_{13}=\left[\left(I_{x}+I_{y}\right) / 2 I_{b}\right]^{0.15} \leq 1
$$

where, $I_{x}$ and $I_{y}$ are the average moments of inertia of columns in $x$ and $y$-directions of the critical storey. Similarly, $I_{b}$ is the moment of inertia of the most common beam at the top level of the critical storey. If the critical storey has no beams, as in the case of flat slabs, then a flat value of $f_{13}=0.60$ will be used.

The degree of confinement by transverse ties at both ends of columns is also considered as a quantitative correction parameter. Since, the most earthquake codes require a maximum transversal tie spacing of $100 \mathrm{~mm}$, if the existing tie spacing of the column ends is $s>100$ $\mathrm{mm}$ at the critical storey, the correction factor $f_{14}$ is defined as:

$$
0.60 \leq f_{14}=(100 / s)^{0.25} \leq 1
$$

Although, the proposed method is developed mainly for residential buildings it may be extended to some other types of buildings, such as schools and hospitals, simply by reducing the final score in relations to the importance coefficient $I_{b}$ of the building which ranges between $I_{b}=1$ to 1.5 in the Turkish Earthquake Code of 1998 (TEC'98). Hence, the correction factor $f_{15}$ is defined as

$$
f_{15}=1 / I_{b}
$$

The proposed P25 Scoring Method is based on the collapse vulnerability of buildings at the highest earthquake risk zone for the maximum level of effective ground acceleration coefficient $A_{0}$, that is $A_{0}=$ 0.4. On the other hand, for lower level of earthquake risk zones, the effective ground acceleration coefficients are gradually reduced from $A_{0}=0.40$ to $A_{0}$ $=0.30, A_{0}=0.20$ and $A_{0}=0.10$. Therefore, at relatively lower levels of earthquake risk zones, rather than decreasing the final score of the building, the final score $P$ is increased by the ratio of the maximum effective ground accelerations 0.40 to that of the corresponding earthquake zone. Hence the correction factor $f_{16}$ is defined as:

$$
f_{16}=0.40 / A_{0}
$$

\section{Further Applications}

\subsection{Reliability of the Method}

The previously presented studies by Bal et al. [13, 14] were based on verifications with 26 partly and totally collapsed or non-damaged buildings. Since then, the total number of case-studies is then increased in order to validate and update the reliability of the method as 100 additional building data became available.

One of the serious handicaps of such empirically prepared rapid assessment technique is dependence on a particular region and earthquake damage history. The proposed method may not satisfy the conditions of any 
other region and earthquake data. For instance, a technique based on a set of data chosen from city A may not be able to capture the damage stages of a city B. The character of the dataset employed to develop the methodology plays a major role in such cases. In order to avoid such dependencies, the empirical approach must be established and based on a general set of data. In this study, the example damaged buildings are chosen from six different cities, which suffered extensive damages during five different earthquakes occurred in Turkey between 1967 and 2003.

A total of 126 buildings have been selected for the study that consist of 17 totally collapsed, 27 heavily damaged, 21 moderately damaged, 20 slightly damaged and 19 none damaged buildings under those earthquakes, while 22 of them are newly constructed buildings designed in accordance with to the current TEC'98. Proven to be a sound approach to capture, the collapse vulnerability of buildings the P25 Scoring Method is not expected to classify such recently designed buildings as collapse vulnerable. The main purpose of adding those recently designed buildings to the dataset however, to check the consistency of the method in terms of modern code requirements.

The results of the new dataset are illustrated in Fig. 1 which demonstrates clearly that the P25 Scoring Method is very capable of capturing and even classifying the buildings in accordance with their degrees of vulnerability to damages. At least for the investigated 126 buildings, it may be concluded that the methodology is very successfully verified. A further confirmation and also a more dependable assessment of the approach would be reached if these buildings are also tested by appropriate numerical analyses.

\subsection{Evaluation of Risk Bands}

Although the results obtained for the P25 Scoring Method provides us with a certain opportunity to subdivide the totally collapsed and slightly damaged buildings with a clear line, because of the uncertainties of the parameters, the division between the two categories should rather be made with a relatively wider band called as "the band of detailed evaluation", as shown in Fig. 1.

The high risk band in the figure represents buildings, which are quite vulnerable to total collapse. They should have a higher priority to be demolished or to be urgently retrofitted. Whereas, the band of detailed evaluation represents buildings, which may have a certain risk level of collapse, thus, comprehensive detailed analyses would be essential. Containing the majority of the buildings in a building stock, the low risk band represents quite a high majority of buildings, which have some risk of experiencing very low levels of damages but absolutely no total collapse and no loss of life are expected.

The risk bands are defined by considering the condition of life safety, aiming at "zero" loss of life. Life safety limits of the bands are decided statistically by expanding the $P$-score up to 30 point level with the standard deviation of totally collapsed and no damaged building scores. By this way, the high risk band is defined below $P=15$, while the detailed evaluation band lies between 15 and 40 points. The low risk band is located above 40 points. However, the risk bands may be adjusted depending upon the economical circumstances of the country. For instance, increasing the upper bound of the detailed evaluation band basically would mean to include more buildings into the categories of retrofit.

One can say that retrofitting a building before experiencing a strong earthquake may not create an additional financial difference since that building will need to be retrofitted after the event anyhow, so the cost would be the same or even less. However, for most buildings, the post-event cost usually consists of not only the cost of retrofitting of buildings but also the indirect losses, which are generally much bigger than the direct losses. The cost-benefit analysis demonstrated in Fig. 2, indicates clearly that the assumedindirect losses are almost double of the direct losses $(i=2 d)$. 


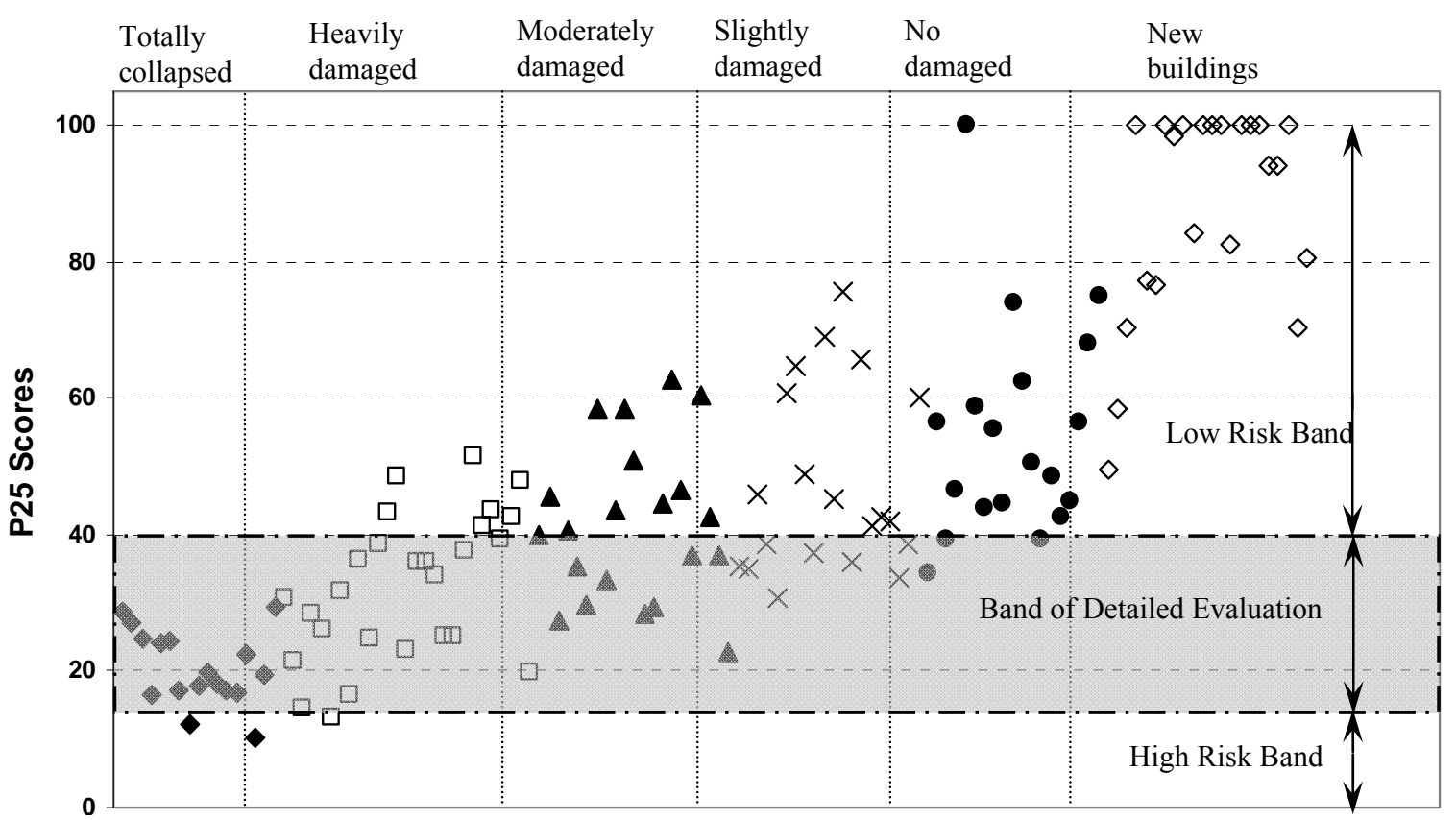

Fig. 1 Distribution of scores and the band of buildings for "detailed evaluation”.

Cost-Benefit Analysis of Mitigation via P25 Method

(Model 2, i=2d)

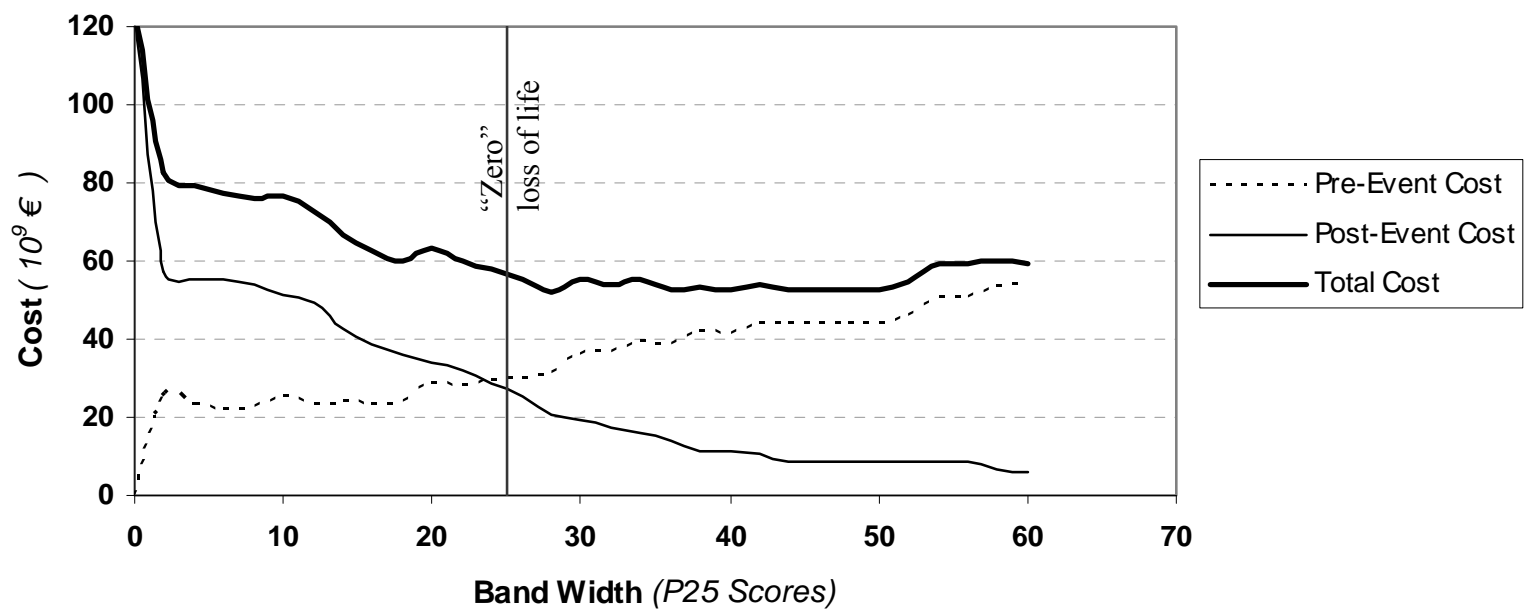

Fig. 2 Cost-benefit analysis in terms of direct and indirect losses.

The band width of detailed evaluation is increased step by step and the total recovery costs of damaged buildings within the band are calculated by mean damage ratios. The mean damage ratio is simply the ratio between the recovery cost and the replacement cost of a building. These ratios are given as $104 \%$ for totally collapsed, $105 \%$ for heavily damaged, $33 \%$ for moderately damaged and $16 \%$ for slightly damaged buildings [14]. It should also be noted that the number of buildings within the band does not represent the real damage distribution, so these numbers of damaged buildings are justified with real average damage ratios caused by the 1999 Kocaeli, Yalova, Sakarya and Duzce Earthquakes in Turkey. Those values are $6 \%$ totally collapsed, $6.7 \%$ heavily damaged, $12.3 \%$ moderately damaged, $13.7 \%$ slightly damaged and $61.3 \%$ non damaged buildings [1-3]. Cost calculations should be done using these real 
damage ratios rather than the evaluation results of the selected database. Operational costs (demolishing, retrofitting, etc.) should be also calculated on the basis of historically experienced damage ratios.

\subsection{Sensitivity Analysis}

A sensitivity analysis dealing with the proposed P25 Scoring Method has been also conducted in order to examine the sensitivity of the parameters used. Sensitivity analysis is essentially based on varying the original parameters of the case study buildings and recording the increase or decrease of the final score. Through such procedure the parameter sensitivity of the damage stages may be tested.

The sensitivity analysis is carried out by increasing or decreasing the original value of a particular parameter by $50 \%$ and then updating the scores of all case study buildings. The average percentage deviations of the score of the initial base model have been calculated as shown in Fig. 3 .

As seen in Fig. 3, the final score is found to be most sensitive, in descending degree of importance, to soft storey assessment, to total building height, to discontinuity of vertical structural elements, to column areas, to stirrup spacing. Therefore, in order to increase the accuracy of the P25 Scoring Method, a more careful evaluation should be performed for the above mentioned parameters.

\section{Conclusions}

In this study, the P25 Scoring Method proposed for the rapid assessment of collapse vulnerability of buildings. It is calibrated rigorously on the base of 100 new example buildings. It is demonstrated that the

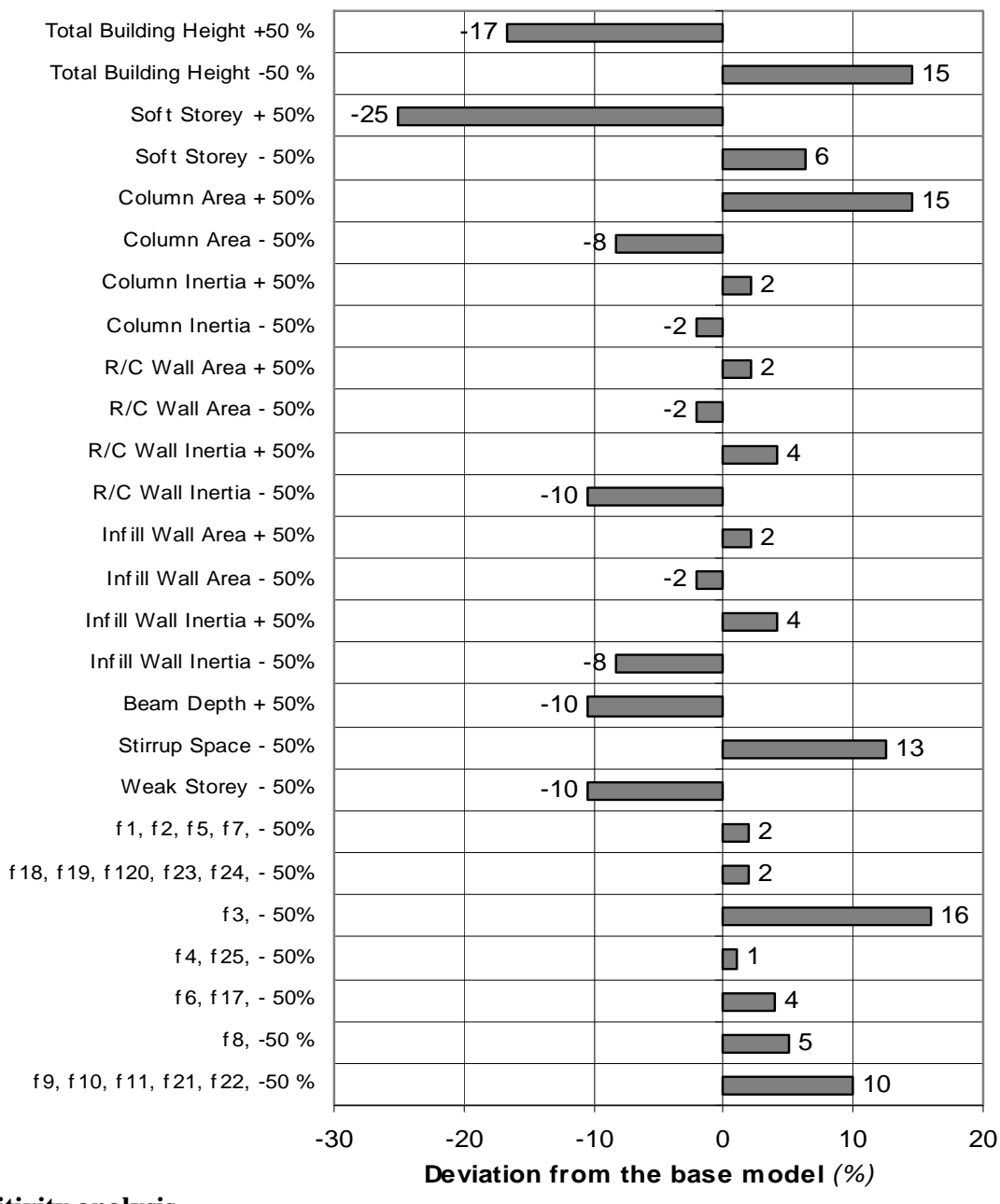

Fig. 3 Results of sensitivity analysis. 
proposed method is able to capture the collapse vulnerabilities of buildings chosen from different geographical and seismic environments. The P25 Scoring Method predicts also correctly, the expected damaged levels of the buildings designed most appropriately in accordance with the new Turkish Earthquake Code of 1998.

One of the most intricate aspect of such rapid assessment technique is the evaluation of the band between the two extreme damage levels. A reasonable band of for detailed analytical investigations is proposed on the basis of life safety and cost benefit analyses. Several models are created for this purpose but only the Model 2 is presented in this paper. Model 2 assumes that the indirect losses will be double of the direct losses after a strong earthquake. It should be noted however the costs given for this study may not be precise since the loss estimation is another complicated subject of earthquake engineering studies and it is still being investigated extensively by several researchers. However, in order to compare the effects of the bandwidth modifications, an overall cost estimation has been provided.

The sensitivity of the parameters utilized in the proposed method is also investigated. The soft storey parameter $f_{12}$ for example is found to be the most effective parameter on the total $P$ score. The overall height of the building is also found to be quite effective on the results of the method. The discontinuity of the vertical structural elements in a building is identified as the third most important parameter of the method. Transversal reinforcement spacing within the confinement areas of columns and also the total column areas in the critical storey are also determined to be the other most important and effective parameters of the P25 Scoring Method.

The life safety condition is satisfactorily satisfied by means of a relatively larger existing between 15 and 40 points. The life safety requirement is found to be accessible if half of the total losses likely to occur during a future earthquake is spent for retrofit operations. One should also notice that direct losses given in Fig. 3 include the assessment and also the operation costs, such as retrofitting, demolishing and replacing a building.

\section{References}

[1] S. S. Tezcan and M. Gursoy, Municipal obligations for earthquakes, in: Proceedings of the Regional Workshop on Seismic Hazard and Risk Management, Tsakhadzor, Armenia, 2002.

[2] S. S. Tezcan and I. E. Bal, Zero loss of life project during a future earthquake, in: 32nd International Geological Congress, Florence, Italy, Aug. 20-28, 2004.

[3] S. S. Tezcan, I. E. Bal, An assessment procedure for zero loss of life during earthquakes, in: Proc. EE-21C, Earthquake Engineering in the 21st Century, IZIIS, International Center for Earthquake Engineering and Engineering Seismology, Skopje, Macedonia, 2005.

[4] S. S. Tezcan, K. Kaptan and I. E. Bal, Risk management techniques for future earthquakes, in: Proceedings Macedonian Association of Structural Engineers Symposium, Skopje, Macedonia, 2005.

[5] A. F. Hassan and M. A. Sozen, Seismic vulnerability assessment of low-rise buildings in regions with infrequent earthquakes, ACI Structural Journal 94 (1) (1997) 31-39.

[6] P. Gulkan and M. A. Sozen, Procedure for determining seismic vulnerability of building structures, ACI Structural Journal 96 (3) (1999) 336-342.

[7] A. C. Pay, New methodology for the seismic vulnerability assessment of existing buildings in Turkey, M.Sc. Thesis, Department of Civil Engineering, Middle East Tech. Univ., Ankara, Turkey, Aug. 2001.

[8] I. E. Bal, S. S. Tezcan and G. Gulay, P25 scoring method for a rapid assessment of collapse vulnerability of reinforced concrete buildings, Engineering Structures, 2006. (accepted)

[9] F. F. Baysan, Assessing an existing building by both structural analysis and Japanese seismic index method, Master Thesis, Civil Engineering Department, Istanbul Technical University, 2002.

[10] H. Boduroglu, P. Özdemir, A. Ilki, S. Sirin, C. Demir and F. ve Baysan, Towards a modified rapid screening method for existing medium rise RC buildings in Turkey, in: 13 WCEE, 13th World Conference on Earthquake Engineering, Vancouver, B.C., Canada, Aug. 1-6, 2004.

[11] G. Ozcebe, A. Yakut and M. S. Yucemen, A statistical procedure for the assessment of seismic performance of existing reinforced concrete buildings in Turkey, in: 13 
WCEE, 13th World Conference on Earthquake Engineering, Vancouver, B.C., Canada, Aug. 1-6, 2004.

[12] A. Yakut, P. Gulkan, B. S. Bakır and M. T. Yilmaz, Re-examination of damage distribution in adapazari: structural considerations, Engineering Structures 27 (2005) 990-1001.

[13] I. E. Bal, Rapid assessment techniques for collapse vulnerability of reinforced concrete buildings, M.Sc.
Thesis, Istanbul Technical University, Faculty of Civil Engineering, 2005. (in Turkish)

[14] I. E. Bal, H. Crowley, R. Pinho and G. Gulay, Structural characterisation of Turkish reinforced concrete building stock for loss assessment applications, in: 1st European Conference on Earthquake Engineering and Seismology, Geneva, Switzerland, Sep. 3-8, 2006. 